\title{
Peculiar Ophthalmic Proliferations
}

\author{
JOAN MULLANEY \\ Dublin, Ireland
}

\begin{abstract}
Summary
Six unusual cases diagnosed by various scientific methods are described to highlight the role of the histopathologist in clinical ophthalmology. The first case shows the importance of fast tissue diagnosis to prevent possible radical treatment in a limbal pseudotumour. The second presentation is of a small conjunctival mass with orbital involvement, immunohistochemically a B-cell lymphoma and occurring after a recent testicular tumour. The third patient presented with the rarely described nodular hypersensitivity conjunctivitis (Splendore-Hoeppli reaction) and it is suggested that these ophthalmologically observed asymptomatic lesions are apparently clinically transient so reports may be few because of infrequent biopsy. Pan-uveal melanocytic tumours concurrent with thoracic or abdominal carcinoma are reviewed. DNA flow cytometry could, perhaps, assess those ocular lesions for malignancy. The fourteenth case in the literature of lacrimal sac melanoma and possibly the first by tear seedling is illustrated. Lastly, a paediatric orbital fibrous histiocytoma is a cautionary anecdote with successful outcome.
\end{abstract}

I am very honoured to be chosen as the 4 th European Guest Lecturer. I felt that I would take rare and interesting clinical ophthalmological conditions and illustrate the role of a histopathologist in their identification. Most of the cases described presented as spaceoccupying lesions which, on microscopic examination, showed a wide variety of pathological reaction, with often an obscure aetiology. Management and prognosis where relevant are discussed.

Firstly, three interesting conjunctival proliferations are presented.

\section{Case Reports}

(1) A 64 year old farmer was referred with a history of a sore red eye for seven months and of having had 'grit' removed by the local nurse, in the left eye 18 months pre- viously following shaking straw. Vision was normal. On clinical examination there was a raised hard ridge of tissue above the limbus extending from 8 o'clock to 2 o'clock, with hyperaemia of the overlying and upper bulbar conjunctiva. No foreign body was demonstrated on radiological examination. In view of the extent of the lesion and its consistency, carcinoma was considered a definite possibility. A biopsy with frozen section control was proposed and, if positive, enucleation should follow. However, the patient refused enucleation. An excision biopsy was performed. Histopathology of the small piece of tissue showed a chronic inflammatory lesion with fibroblasts sometimes in fascicular arrangement with many plasma cells and many eosinophils. The overlying conjunctival epithelium had undergone squamous meta-

European Guest Lecturer, Oxford Ophthalmological Congress, July, 1989.

Correspondence to: National Ophthalmic Pathology Laboratory \& Registry of Ireland, Royal Victoria Eye \& Ear Hospital, Adelaide Road, Dublin 2, Ireland. 


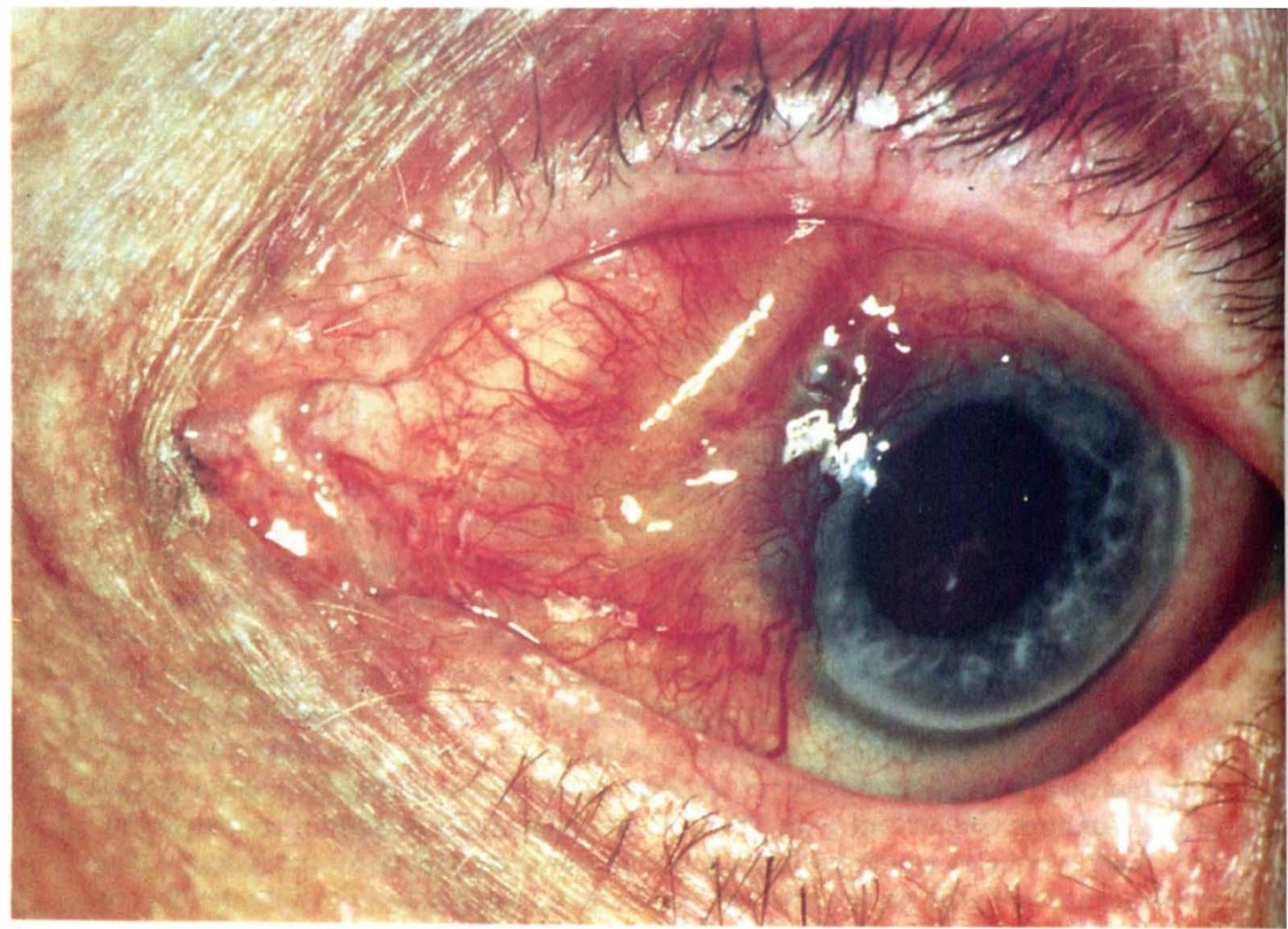

Fig. 1 Case 1. Limbal pseudotumour. (Courtesy of Mr Maurice Fenton)

plasia. The specimen was serially sectioned but no foreign body, fungus helminth or seed husk remnant could be identified. Malignancy was not found. This was an example of limbal pseudotumour with severe chronic inflammation and architectural changes suggestive of fibrous histiocytoma. Three months later there was still some minor thickening and slight congestion. However, after eight years there is only a minute scleral scar at approximately 10 o'clock, in a white eye (Figs.1 and $2)$. The case is presented to indicate the importance of the invocation of frozen sections examination during operation for the assessment of a large suspicious limbal lesion if enucleation is contemplated.

(2) A 66 year old man presented with a left conjunctival nodule in July, 1988 and a history of orchidectomy in April, 1988 for seminoma. The conjunctival biopsy revealed itself to be a lymphomatous condition and, with histochemistry, it was evident that it was a small B-cell lymphoma. A month after the conjunctival lesion he was referred to the orbital clinic with progressive downward displacement of the left globe. A transeptal biopsy showed that he now had a lymphoma (small B cell type) occupying the upper temporal quadrant of the orbit.

In view of the rarity of primary orbital lym phomas his testicular biopsy was re-evaluated and the diagnosis was revised from that of seminoma to lymphoma (Fig. 3). He was referred to the Oncology unit and a full CT scan and bone marrow aspirate were normal. He was commenced on combination therapy BACOP/Bleomycin, Adriamycin, Cyclophosphamide, Oncovin (Vincristin), and Prednisolone with six courses in all. The orbital lesion clinically resolved after four of the six courses. At the time of writing he is apparently well. In this patient histopathology and histochemistry were important. The latter was used to re-evaluate the conjunctival, orbital and testicular lesions. The monoclonal markers, namely the common leucocyte antigen (CLA) reliably marking $90 \%$ of the B cells identified in this case, can be done on paraffin sections. Placental leucocyte acid phosphatase (PLAP) (positive in seminoma) 


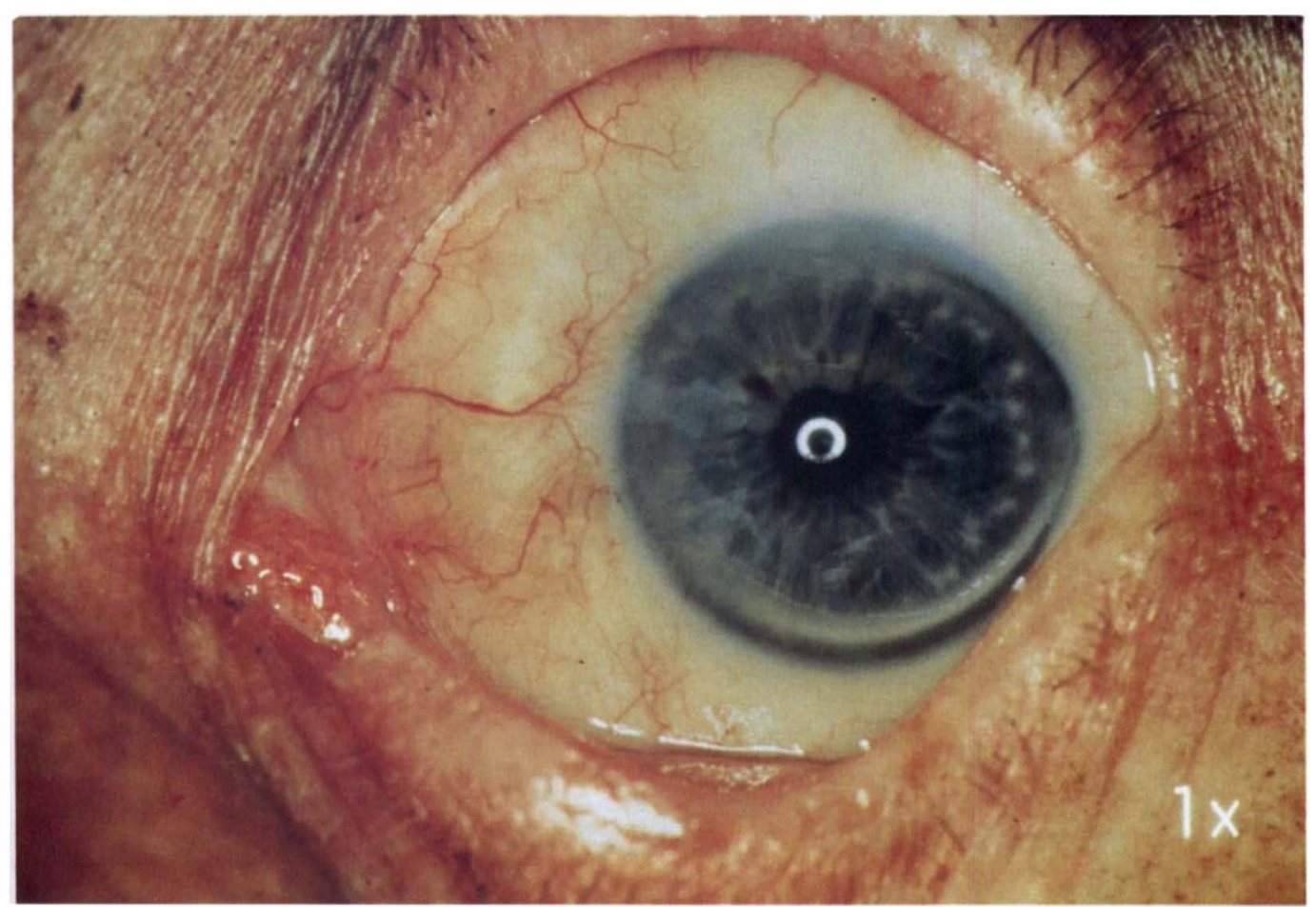

Fig. 2 Case 1. Scar eight years after surgery.

was negative in the testicular, conjunctival and orbital lesions. This case is of considerable interest as seminoma histologically may resemble a lymphoma but treatment differs from that of a seminoma.

(3) A 39 year old male patient had bilateral recurring dendritic ulcers from childhood which were quiescent. A routine examination in July 1983 showed small white nodules on the left bulbar conjunctiva underneath the upper lid with some hyperaemia (Fig. 4). After excision biopsy of these nodules he received chloromycetin ointment three times a day for a week. Histological examination of the nodules showed eosinophilic necrosis (Fig. 5) surrounded by epithelioid and mononuclear cells with occasional giant cells of Langhan's type, numerous eosinophils as well as some plasma cells and lymphocytes. One month later two nodules reappeared. They were once again treated with chloromycetin and subsided. On 15 February 1984 the patient was seen with a similar nodule on the right conjunctiva which also regressed on treatment.
These findings conform to the hypersensitivity reaction known as the SplendoreHoeppli phenomenon first described in the bulbar conjunctiva and well summarised by Ashton and Cook. ${ }^{1}$ The eponyms arise from Splendore $^{2}$ working in Brazil who described this reaction with a pulmonary fungus and Hoeppli $^{3}$ in China who observed it with schistosoma ova. There is a slight air of desperation in the search for the causative agent of the rather typical histology. Bacteria (streptococci), fungi, helminths, viruses, chlamydia trachomatis and even insects (warble fly) have been incriminated. The patient illustrated here had a long corneal herpetic history with treatment and the conjunctival nodules, never limbal, were apparently intermittent and causing no particular clinical disturbance. Case reports are extremely rare in the literature but discussions with numerous ophthalmologists would indicate that (a) these nodular proliferations are clinically not infrequently seen, (b) they may be asymptomatic, (c) hyperaemia can be slight, and (d) they seem to retrogress. The presence of numerous 


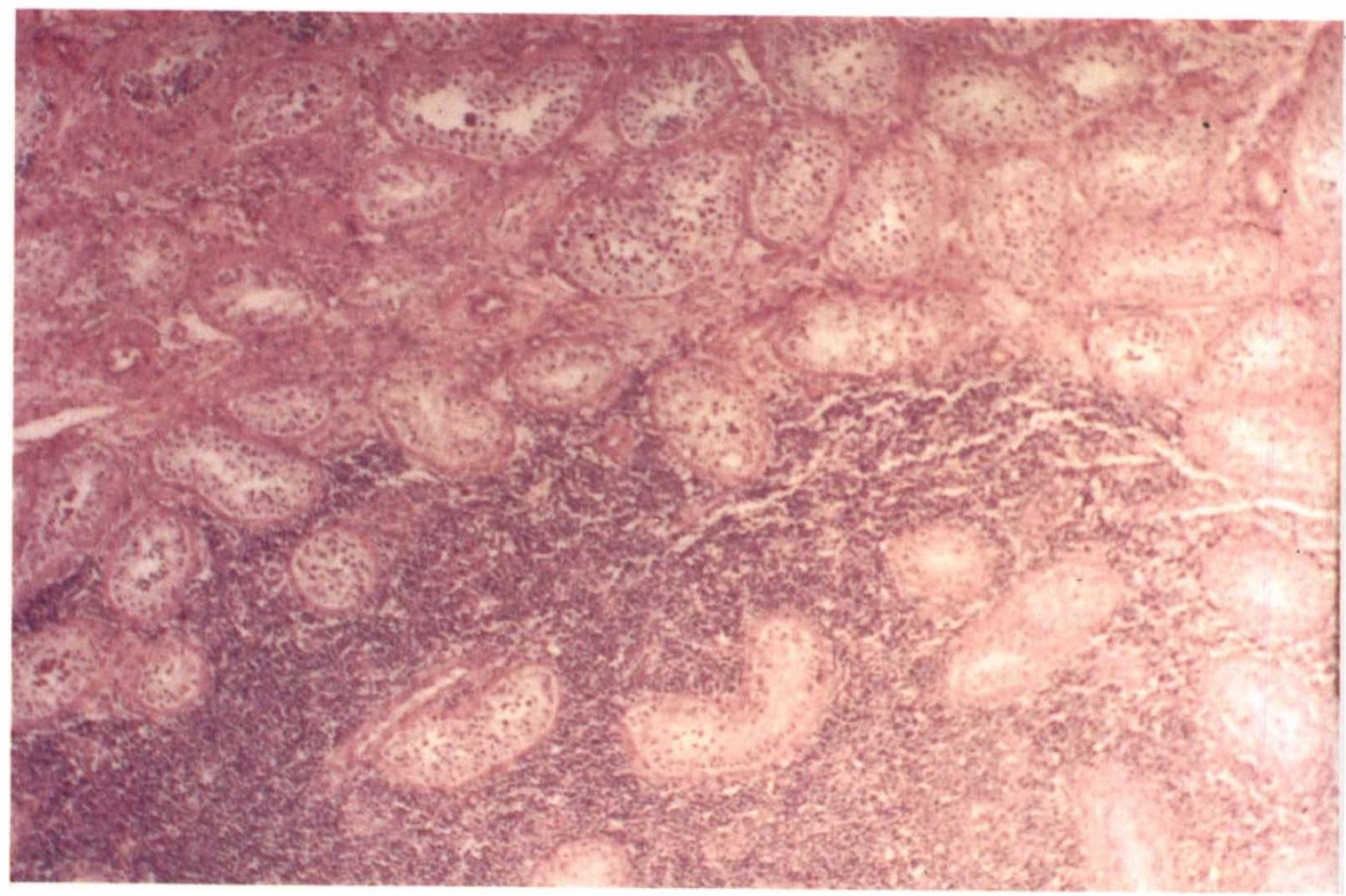

Fig. 3 Case 2. Testicular tubules with lymphomatous infiltration.

eosinophils suggests a hypersensitivity reaction of as yet undetermined aetiology. Further studies are necessary to assess if this condition is of any real clinical significance when the aetiology is unknown or whether it is merely a passing pathological curiosity.

Actinic granuloma has similar microscopic findings to the Splendore-Hoeppli phenomenon but there are no eosinophils. Swimming pool granuloma with marked injection of the conjunctiva caused by mycobacterium marinum is another histological differential diagnosis, but the organisms can be demonstrated in the lesions. It sometimes imitates Parinauds ocular glandular syndrome.

Next, problems relating to the melanocytic system will be considered.

The vast literature on the pathology of the ocular pigmentary apparatus might suggest that the emergence of still obscure melanocytic lesions would be unlikely, but interesting facets can still be discovered. For example, free DNA was seen by light microscopy in two necrotic choroidal melanomas ${ }^{4}$ in the form of lakes confirmed as being DNA by transmission electron microscopy and show- ing a direct continuity between a lake and the nuclear chromatin. Jensen (personal communication 1989) had not found DNA in melanomas again. I have observed it in two specimens (Fig. 6). No other reports to date have appeared which is surprising in view of the common occurrence of necrotic uveal melanomas. The distribution of this free DNA in melanoma appears to differ from that found in retinoblastoma. An ultrastructural examination was found to be necessary to demonstrate the presence of small discrete electron dense DNA granules $60-200 \mathrm{~nm}$ in retinoblastoma. ${ }^{5}$ These deposits have an affinity for collagen and basal lamina, especially in the iris and they were not phagocytosed by trabecular endothelial cells. Examination by transmission electron microscopy of the anterior segment in globes containing necrotic uveal tract melanoma may give findings analogous to those found in retinoblastoma for free DNA deposition.

DNA in tumours can be measured by flow cytometry. A comparison of nuclear/nucleolar size in melanoma cells can be measured by. allowing the nuclei, stained with a fluorescent 


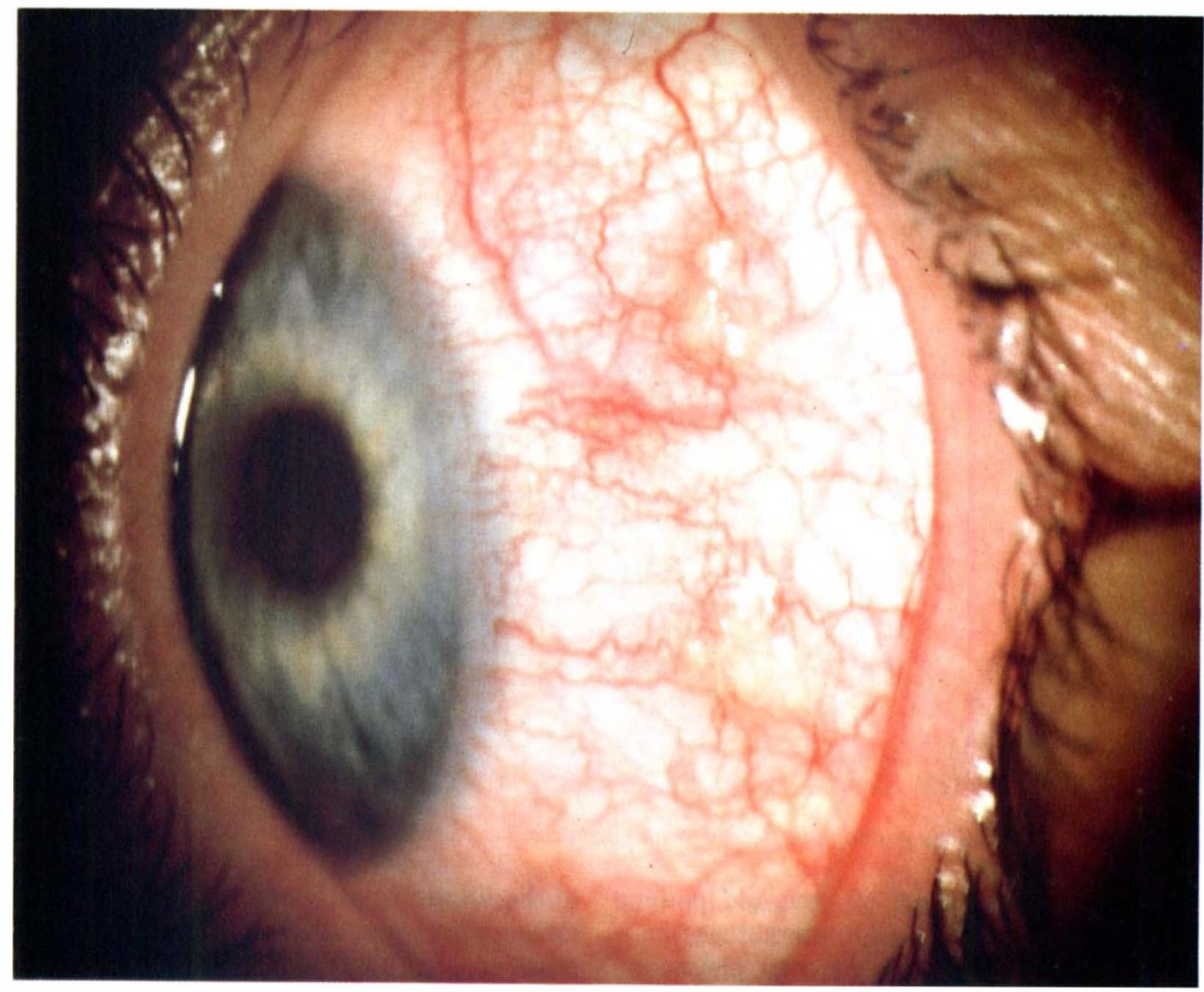

Fig. 4 Case 3. Hypersensitivity nodular conjunctivitis (Splendore-Hoeppli phenomenon). Courtesy of Dr. Denis Wilson.

dye, to flow past a laser beam and the resulting light emanations are plotted on a histogram. ${ }^{6}$ This method can be used on paraffin and retrospective studies are therefore possible. Fresh specimens give more sensitive readings. Normal cells have a diploid complement of DNA, ie two each of the autosomes but most tumour cells may be aneuploid with increased numbers of chromosomes. The more aneuploid the tumour the worse the prognosis in melanomas. Ploidy abnormalities correlated with survival better than the usual histological parameters. ${ }^{7}$ However, in contra distinction to melanomas large retinoblastomas are said to have a normal ploidy level and this analytical method did not offer information either about risk of metastases or the degree of anaplasia ${ }^{8}$ in these tumours. The reasons for this are not understood and further analysis is necessary.
Retrospective studies by flow cytometry for ploidy abnormalities might be used to study the pathological material from the eight cases reported from 1966 to $1985^{9-12}$ of a new syndrome with diffuse bilateral uveal melanocytic lesions and concurrent abdominal or thoracic carcinomas. This is suggested as there appears to be disagreement using light microscopic methods of examination on the enucleated specimens as to whether these rare uveal tract lesions are naevi or melanomas (de Wolff-Rouendaal, 1989 personal communication). Six of the eight reported cases presented first with increased visual loss but on subsequent examination were found to have malignant epithelial tumours of pancreas, large intestine, lung, ovary and gall bladder. A general autopsy was performed on four patients but all eight cases had eyes studied microscopically. The primary malignancy was 


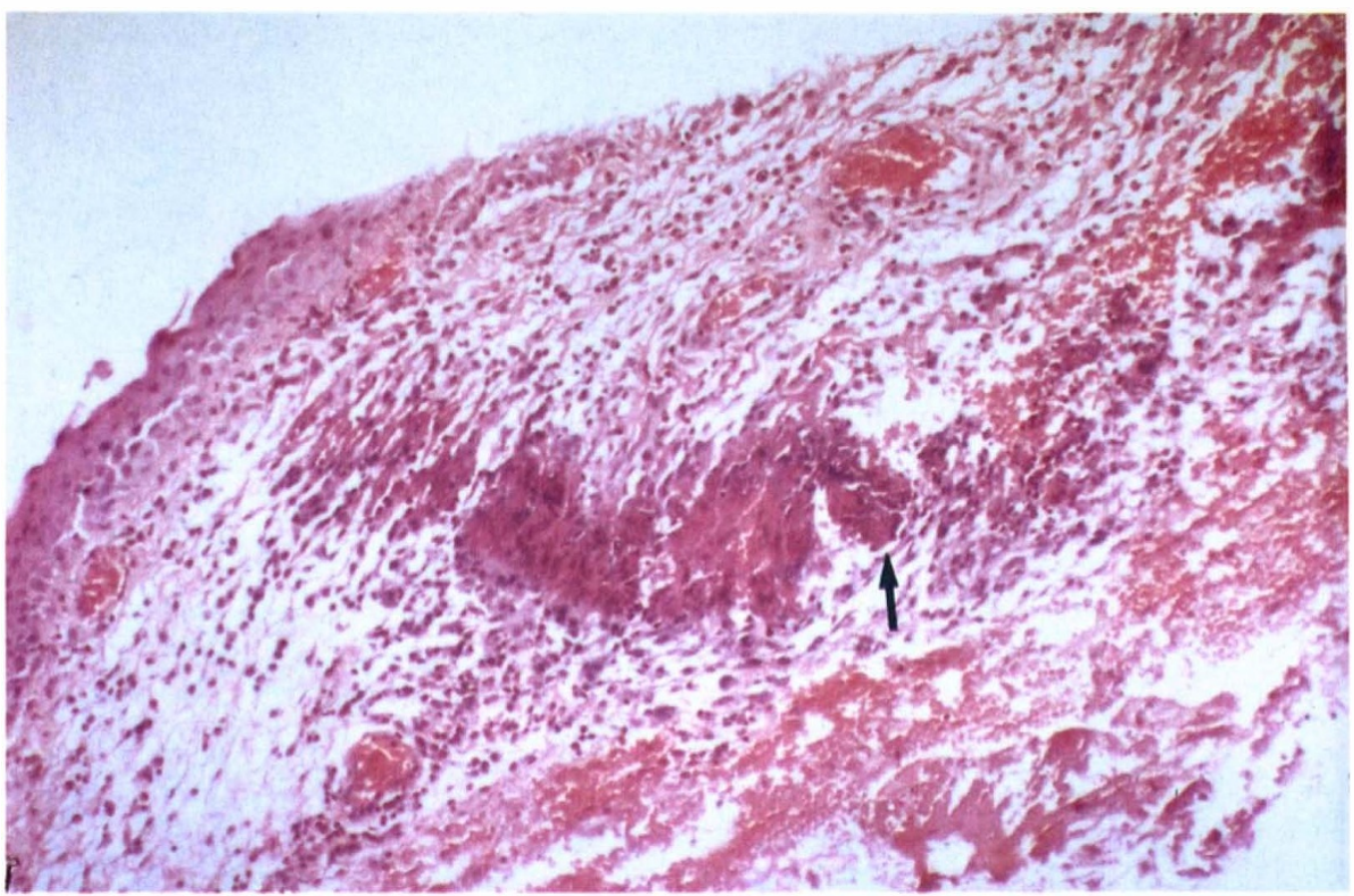

Fig. 5 Case 3. Histology eosinophilic necrosis with giant cells.

the cause of death. A 60 year old patient which we described ${ }^{13}$ had bilateral lens opacities, left iris protrusion, macular elevation, patchy fluorescence and irregular fundal pigmentation on presentation. After three months vision was reduced to hand movements. There was rubeosis and extensive retinal detachments. The patient developed disseminated intra-vascular coagulation and died. Ocular histopathology, post mortem, showed diffuse pan uveal melanomata with an occasional mitosis. Only one globe of the reported cases was examined by transmission electron microscopy. Melanosomes were identified in the lesions. The histopathology was most suggestive of melanoma and the secondary effects on the globe were those of a rapidly proliferating lesion. The differential diagnoses of these unusual ocular changes are bilateral pigmented lesions on the fundus, bilateral hypertrophy of the pigment epithelium, toxic retinopathy, diffuse uveal malignant melanoma, reactive lymphoid hyperplasia, leukemic infiltrates, multiple melanocytomas, metastatic disease or reticulum cell sarcoma. ${ }^{10}$ There are only 18 reports in the literature of bilateral uveal malignant melanomas ${ }^{11}$ and diffuse malignant melanomas are very rare ${ }^{14}$ and bilateral ocular carcinomatous metastases were uncommon in 10 of 196 eyes containing metastases. ${ }^{15}$ Further case descriptions are awaited with interest.

Precancerous melanosis, classified under primary acquired melanosis by the WHO group $^{16}$ usually invokes a lively discussion about microscopy and management. A patient with precancerous melanosis and multiple melanomata developed a very rare complication.

A 65 year old healthy man (normal vision) presented in 1977 with a pigmented spot of five years' duration under his right lower lid. It was excised and was histologically a conjunctival melanoma. During the next 11 years he had five other melanomata removed from different lid and bulbar sites. Exenteration was contemplated but was decided against in 1981. He received chemotherapy in 1985 . Epistaxis occurred in December 1988. He was admitted in January 1989 for exploration of the lacrimal sac where there was a hard black nodule filling the sac and involving the can- 


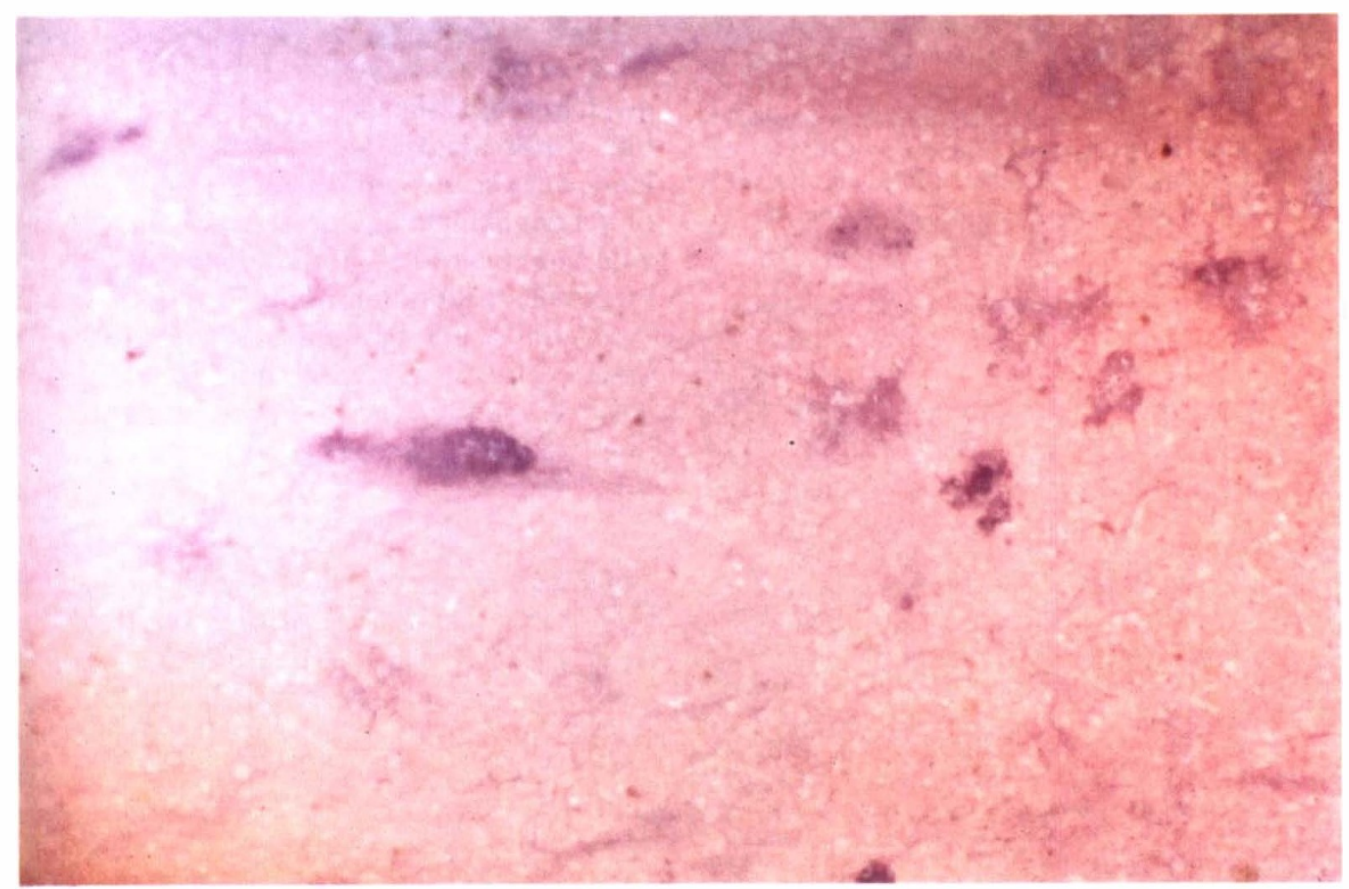

Fig. 6 DNA 'lakes' in necrotic melanoma.

aliculus. This mass appeared to be a tumour and excision of lacrimal sac, canaliculi, nasolacrimal duct and medial and canthal ligaments were performed. Histology showed a heavily pigmented poorly differentiated necrotic melanoma with extension into the neighbouring muscle. Serial sections failed to show extension from conjunctiva. Ear, nose and throat examination showed nothing abnormal in these cavities. At the time of writing his right VA is $6 / 24$, left VA is $6 / 9$ with good closure of the lids. When he presented with this last lesion he had conjunctival melanosis but no tumour and it is postulated that this is either a new tumour arising in the lacrimal sac from residual primitive melanin producing cells developing in the sac during fetal ectodermal downgrowth or a secondary seedling perhaps carried in by tears. Only 13 cases ${ }^{17}$ of primary melanomas in the lacrimal sac have been reported but these patients did not have precancerous melanosis. This would appear to be the fourteenth lacrimal sac melanoma and to be the first recorded in precancerous melanosis perhaps from a tear seedling.

Other rarities may still be discovered in the lacrimal sac. Thus, Blake and Mullaney ${ }^{18}$ reported the fifth case of mucoepidermoid carcinoma at this site. The previous reports were two cases from Brazil ${ }^{19}$ and two cases from China. ${ }^{20}$ The incidence of mucoepidermoid carcinoma may be much greater than the literature indicates. A faulty diagnosis of transitional cell carcinoma may frequently have been made. Simple histochemical stains for mucin can help to differentiate and this can be further confirmed by transmission electron microscopy. Mucoepidermoid carcinoma carries a worse prognosis than the others at this region and exenteration is said to be the procedure of choice in these cases.

Finally, the importance of accurate histopathological diagnosis in relation to an orbital tumour is demonstrated by the following patient whom I presented at the 1978 Meeting of the European Ophthalmic Pathology Society in view of the importance of the diagnosis and of its rarity and a thirteen year follow-up can now be reported. ${ }^{21}$

A two year old girl had a swelling medial to her left eye which was said to have been present since birth. She had mild proptosis, 


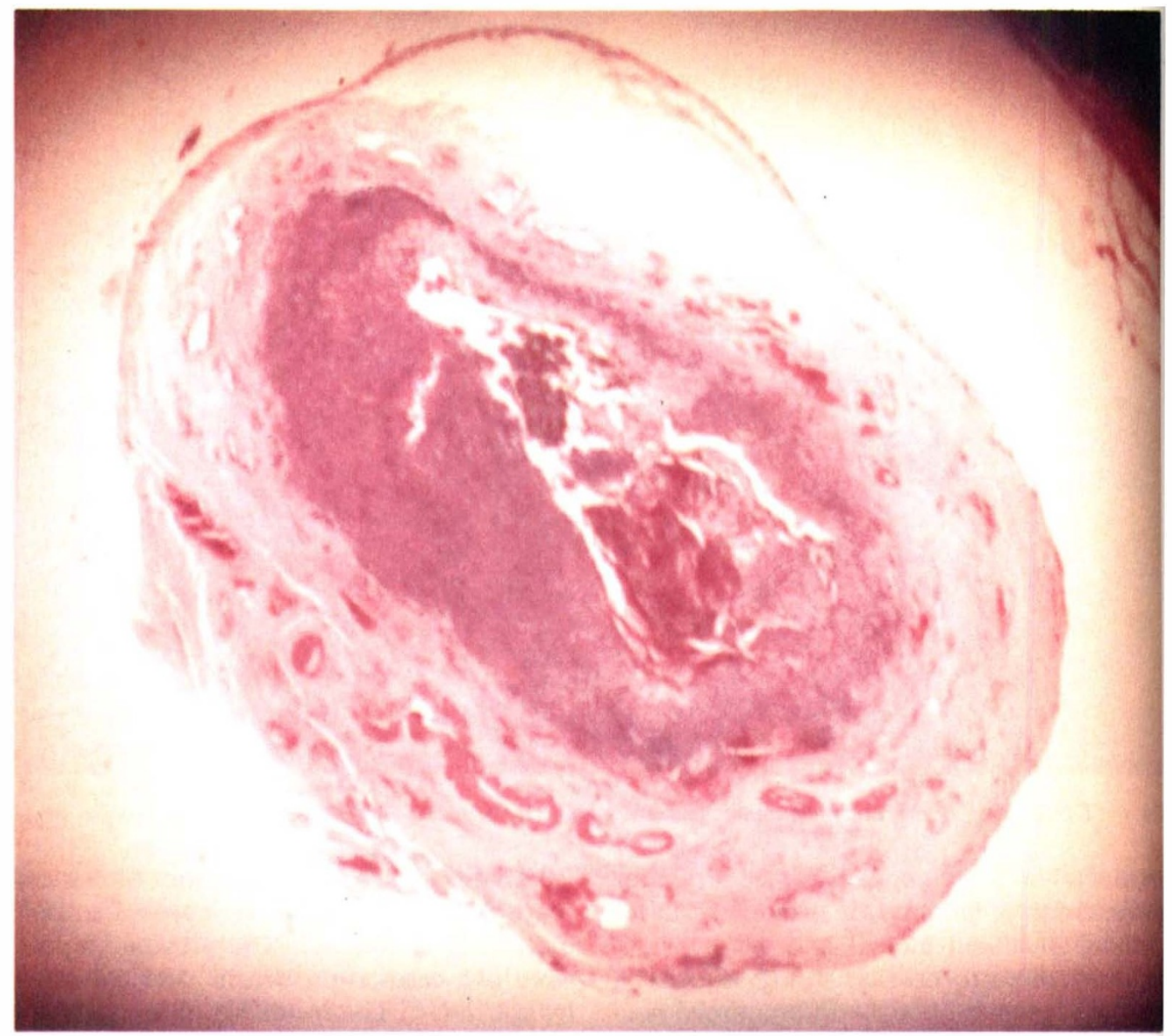

Fig. 7 Lacrimal sac filled with melanoma.

normal vision and left optic disc swelling. Investigation indicated that she had an invasive orbital tumour which, at surgery, was found to enter the ethmoid and nasal regions. The histological diagnosis was orbital fibrous histiocytoma. She had two recurrences at the age of three and eight years treated by surgery with chemotherapy. She is now fifteen years of age. She has no epiphora, $5 \mathrm{~mm}$ of enophthalmos, $4 \mathrm{~mm}$ of globe depression and normal ocular movements. VA right is $6 / 5$, left $6 / 12$ with slight left optic disc deformity. This case illustrated very well the emphasis which must be put on accurate histopathological diagnosis in the management of this tumour. This girl, now thirteen years after initial surgery for her definitely invasive growth, appears still to be free of tumour. ${ }^{21}$

Rhabdomyosarcoma, other soft tissue sar- comata or a metastases from an embryonal tumour enter as important differential diagnoses if the patient is a child. Fibrous histiocytoma is extremely rare in infants and children. Our case appears to be the youngest ever diagnosed at that time in mid 1978 but earlier that year a single case was recorded in a one year old child. ${ }^{22}$ An analysis of 150 cases of orbital fibrous histiocytoma had patients ranging from four years of age upwards and the median was 43 years. ${ }^{23}$ A single case of this tumour in a nine month old infant ${ }^{24}$ required ultrastructural and immunohistochemical studies, demonstrating the presence of vimentin to distinguish the lesion from juvenile xanthogranuloma and eosinophilic granuloma (histiocytosis X). Fibrous histiocytoma derives from undifferentiated mesenchymae and the stem cells differentiate into fibroblasts 
or histiocytes. This parentage may yield a wide range of histological findings both by light microscopy, transmission electron microscopy and immunohistochemistry and cause considerable confusion in the final diagnosis. The assessment of malignancy in fibrous histiocytoma can be difficult and may require sophisticated immunohistochemistry though even these findings are debatable. ${ }^{23}$ Complete excision of the benign entity which is frequently locally invasive should be done while exenteration is recommended for confirmed malignant forms. ${ }^{22}$

\section{Conclusion}

This paper describes six cases of rare clinical and pathological interest and contains cautionary anecdotes. The material has been used to illustrate the necessity for the close liaison between ophthalmologists and pathologists in this field. Standard biopsy tissue using light microscopy still yields the basic diagnosis in nearly all instances. The use of transmission electron microscopy to elucidate lesions, notably in the tumour area, can be useful.

Immunohistochemistry has become essential for diagnosis both in oncology and in some inflammatory conditions, with particular reference to lymphoid conditions. Advice from the pathologist about the appropriate tissue, ie whether frozen or fixed, can be sought if infrequent requirements such as tissue culture or DNA assessments are desired. The use of special fixatives other than formaldehyde or glutaraldehyde solutions may be necessary for some immunohistochemical techniques. Enucleation specimens should always be sent for histological examination as obviously they may contain unsuspected and occasionally significant pathology. Biopsy specimens ought to be of adequate volume but it is surprising and rewarding what mysteries can be salvaged from even supposedly routine but minute pieces of, for example, conjunctival or orbital tissues.

I wish to thank Mrs. C. Winterbotham for most helpful secretarial assistance.

\footnotetext{
References

${ }^{1}$ Ashton N and Cook C: Allergic granulomatous nodules of the eyelid and conjunctiva. Am J Ophthalmol 1978, 87: 1-28.
}

${ }^{2}$ Splendore A: Sobre acultura d'uma nova especie de cogumello pathogenico. Rec Soc Sci S Paulo 1908, 3: 62 .

${ }^{3}$ Hoeppli R: Histological observations in experimental schistosomiasis. Chinese Med J 1932, 46: 1179.

${ }^{4}$ Jensen OA: DNA 'lakes' in a malignant choroidal melanoma. Ophthalmologica 1979, 179: 348-53.

${ }^{5}$ Loeffler KU and McMenamin PG: An ultrastructural study of DNA precipitation in the anterior segment of eyes with retinoblastoma. Ophthalmology 1987, 94: 1160-8.

${ }^{6}$ Coon JS, Landay AL, Weinstein RS: Biology of disease. Advances in flow cytometry for diagnostic pathology. Lab Invest 1987, 57: 453-79.

${ }^{7}$ Meecham WJ and Char DH: DNA content abnormalities and prognosis in uveal melanoma. Arch Ophthalmol 1986, 104: 1626-9.

${ }^{8}$ Winther J, Ehlers N, Jensen OA, Overgaard J, Prause JM: Predictive value of flow cytometric DNA analysis on fresh retinoblastoma tissue. Acta Ophthalmologica 1988, 66: 217-9.

${ }^{9}$ Machemer R: Zur pathogenese des flachenhaften malignen melanosis. Klin Mosatsbl Augenheilkd 1966, 148: 641-52.

${ }^{10}$ Ryll DL, Campbell RJ, Robertson DM, Trubaker SJ: Pseudometastatic lesions of the choroid. Ophthalmology 1980, 87: 1181-6.

${ }^{11}$ Barr CC, Zimmerman LE, Curtin VT, Font RL: Bilateral diffuse melanocytic uveal tumours associated with systemic malignant neoplasms. Arch Ophthalmol 1982, 100: 249-55.

${ }^{12}$ de Wolff-Rouendaal D: Bilateral diffuse benign melanocytic tumour of the uveal tract. A clinical pathological case history. Internat Ophthalmol 1985, 7: 149-60.

${ }^{13}$ Mullaney J, Mooney D, O'Connor M, McDonald GSA: Bilateral ovarian carcinoma with bilateral uveal melanoma. Br J Ophthalmol 1984, 68: 261-7.

${ }^{14}$ Font RL, Spaulding AG, Zimmerman LE: Diffuse malignant melanoma of the uveal tract. A clinicopathologic report of 54 cases. Trans Am Acad Ophthalmol Otolaryngol 1968, 72: 877-95.

${ }^{15}$ Ferry AP and Font RL: Carcinoma metastatic to eye and orbit. Part 1. Clinicopathologic study of 227 cases. Arch Ophthalmol 1974, 92: 276-86.

${ }^{16}$ Zimmerman LE and Sobin LH: Histologic typing of tumours of the eye and its adnexa. International histologic classification of tumours, No. 24. Geneva. World Health Organisation 1980: 30.

${ }^{17}$ Lloyd WC and Leone CR: Malignant melanoma of the lacrimal sac. Arch Ophthalmol 1984, 102: 104-7.

${ }^{18}$ Blake J, Mullaney J, Gillan J: Lacrimal mucoepidermoid carcinoma. $\mathrm{Br} J$ Ophthalmol 1986, 70: 681-5.

${ }^{19}$ Bambirra EA, Miranda D, Royes A: Mucoepidermoid tumour of the lacrimal sac. Arch Ophthalmol 1981, 99: 2149-50.

${ }^{20} \mathrm{Ni}$ C, Wagoner MD, Wang WJ, Albert DDM, Fan CO, Robinson N: Mucoepidermoid carcinoma of the lacrimal sac. Arch Olphthalmol 1983, 101: 1572-4. 
${ }^{21}$ Larkin DFP, O'Donoghue HN, Mullaney J, Breathnach F: Orbital fibrous histiocytoma in an infant. Acta Ophthalmol 1988, 66: 585-8.

${ }^{22}$ Biedner B and Rothkoff L:-Orbital fibrous histiocytoma in an infant. Am J Ophthalmol 1978, 85: 548-50.
${ }^{23}$ Font RL and Hidayatt AA: Fibrous histiocytoma of the orbit. A clinicopathological study of 150 cases. Human Pathology 1982, 13: 199-209.

${ }^{24}$ Jakobiec FA, Klapper D, Maher E, Krebs W: Infantile sub conjunctival and anterior orbital fibrow histiocytoma. Ophthalmology 1988, 95: 516-29. 